\title{
BRITTLE FRACTURE IN HEAT-AFFECTED ZONES OF GIRTH WELDS OF MODERN LINE PIPE STEEL (X100)
}

\author{
A.-S. BILAT ${ }^{\text {a }}$, A.-F. GOURGUES-LORENZON ${ }^{\mathrm{a}}$, J. BESSON ${ }^{\mathrm{a}}$, G. RICHARD ${ }^{\mathrm{b}}$ and A. PINEAU ${ }^{\mathrm{a}}$ \\ ${ }^{a}$ Centre des Matériaux, Ecole des Mines de Paris, UMR CNRS 7633, B.P.87, F-91003 Evry cedex \\ ${ }^{\mathrm{b}}$ Serimer Dasa, 8 rue Mercier, F-77290 Mitry-Mory \\ anne-sophie.bilat@mat.ensmp.fr, anne-francoise.gourgues-lorenzon@ensmp.fr
}

\begin{abstract}
Girth welds of modern line pipe steel, such as $\mathrm{X} 100$, issued from a pulsed automatic gas metal arc welding, were tested to check their performance in artic temperature conditions. It is shown that an impact specimen at $-20{ }^{\circ} \mathrm{C}$ with a notch placed in the middle of the fusion line could break at low energy $(<40 \mathrm{~J})$. The brittle zone is located in the coarse-grained heat-affected zone of the weld. The reproduction of two heat-affected zones with a thermal-mechanical simulator, Gleeble 1500, allows to determine the mechanical behaviour of representative microstructures of the welded joint. Tension tests with or without notch and impact tests are performed between $-196{ }^{\circ} \mathrm{C}$ and $20^{\circ} \mathrm{C}$. This experimental database is used to fit materials constitutive equations which are used in a finite element code to predict the fracture of the welded joint.
\end{abstract}

Abbreviations used, classed in alphabetic order:

AE: Axisymmetric notched

BM: Base Metal

Cs: Simulated CG+MA microstructure

CG: Coarse-Grained

EDS: X-ray analysis, Energy Dispersive Spectrometry

Fs: Simulated FG microstructure

FG: Fine-Grained

FL: Fusion Line

GMAW: Gas Metal Arc Welding

HAZ: Heat-Affected Zone

IC: InterCritical

KCV: Charpy V-notched specimen
$L$ : Longitudinal direction

MA: Martensite-Austenite

S: Short transverse direction

SEM: Scanning Electron Microscopy

$\mathrm{T}$ : Transverse direction

TMCP: Thermo-Mechanical Controlled Process

TS: Tensile Stress

WM: Weld Metal

X100: modern steel with YS above $100 \mathrm{ksi}(690 \mathrm{MPa})$

YS: Yield Stress

$\Phi_{0}, \Phi:$ minimum diameter of $A E$ specimens

\section{Introduction}

Gas field development requires cost reduction of gas transportation. For that purpose, one solution is to increase gas pressure inside pipes. High strength steels of grade X100 are potentially good candidates for these new applications [1], but the toughness of X100 welded joints needs to be characterized, understood and modelled. The aim of this project is to improve the accuracy of prediction tools of the toughness and defect acceptability in case of an automatic GMAW (Gas Metal Arc Welding) welded joint. A quantitative prediction tool of the risk of brittle fracture is built, adapted to the girth welds of new X100 steels, and a crack initiation criterion in the most critical zones of this welded joint is determined and validated. This study is conducted according to the local approach to fracture methodology [2]. This includes first, metallurgical and mechanical characterization of the girth weld, then, thermal welding cycle simulation of the most critical zones and characterization of their flow and fracture properties and, finally, finite element modelling of brittle fracture initiated at these critical zones.

\section{Materials characterization}

The material under investigation is the girth weld (Figure 1) of an X100 grade gas pipe. The outside diameter is 36 " (914 mm) and the wall thickness $20.6 \mathrm{~mm}$. The girth weld was made with an automatic GMAW system which uses a dual-torch facility with a spacing of $50 \mathrm{~mm}$. 


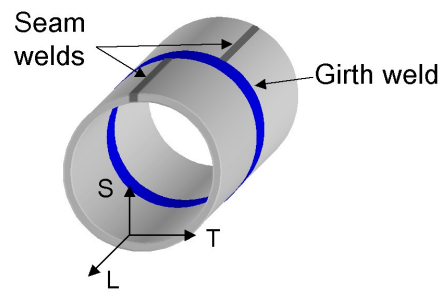

Figure 1. Schematic drawing of tube's welds and orientations notations (L, T, S)

The girth weld consists of three main zones: the base metal (BM), the weld metal (WM) and the heat-affected zone (HAZ).

The modern low carbon steel X100 contains manganese and some silicon, molybdenum and nickel. Niobium and titanium additions allow the control of the steel microstructure during Thermo-Mechanical Controlled Process (TMCP). Hardness and microstructure were thoroughly characterized in each zone (Figure 2, left). Microstructures were examined by optical microscopy after polishing and etching with Nital $2 \%$ reagent, and by SEM after polishing and etching with Villela reagent.
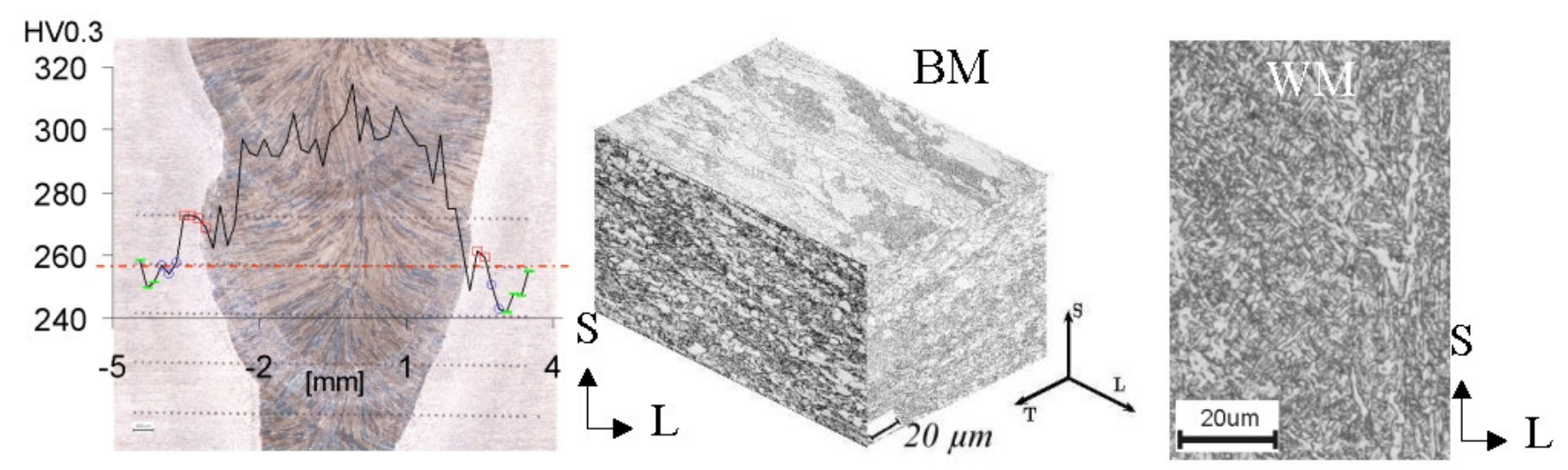

Figure 2. Hardness values according to the location in the girth weld and microstructures of BM and WM

The BM microstructure is a textured bainitic matrix with ferrite (Figure 2, centre) and some secondary phases like martensiteaustenite (MA), which have a deleterious effect on the toughness properties [3].The WM is acicular ferrite (Figure 2, right). The HAZ is mainly upper bainite, it is divided in this study into two zones: the coarse-grained (CG)HAZ (austenite grain size around $30 \mu \mathrm{m}$, spread over $100 \mu \mathrm{m}$ ) next to the WM and the fine-grained (FG)HAZ (austenite grain size smaller than $10 \mu \mathrm{m}$, spread over 1 to $2 \mathrm{~mm}$ ).

\section{Mechanical tests}

The mechanical strength and the brittle part of the welded joint were characterized by using tensile and Charpy specimens. The specimens were cut from the base metal, from the weld metal and across the weld (Figure 3). The WM specimens were cut "all-weld", along the T direction (WM in Figure 3). The BM round bar specimens were cut along the L direction (BM on the right in Figure 3). The Charpy BM specimen were cut along the T direction (respectively $L$ ) with the crack propagating along the $L$ direction (respectively T) (KCV: D BM and BM). The Charpy specimen were cut across the weld (KCV: D J and J), from the outer or inner subsurface of the tube wall. The tensile specimens $\mathrm{J}$ were centred around the weld. Axisymmetric specimens were machined from BM, WM and HAZ to give the mechanical behaviour of each part.

Both tensile and three points bending experiments were performed on a servo-hydraulic INSTRON 8500 test machine under displacement-control of $5.10^{-4} \mathrm{~s}^{-1}$ and $10 \mu \mathrm{m} . \mathrm{s}^{-1}$ respectively, at various temperatures below $20{ }^{\circ} \mathrm{C}$. Dynamic impact tests were

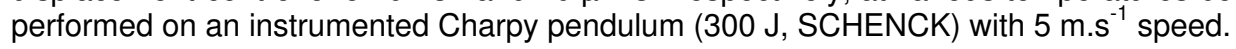




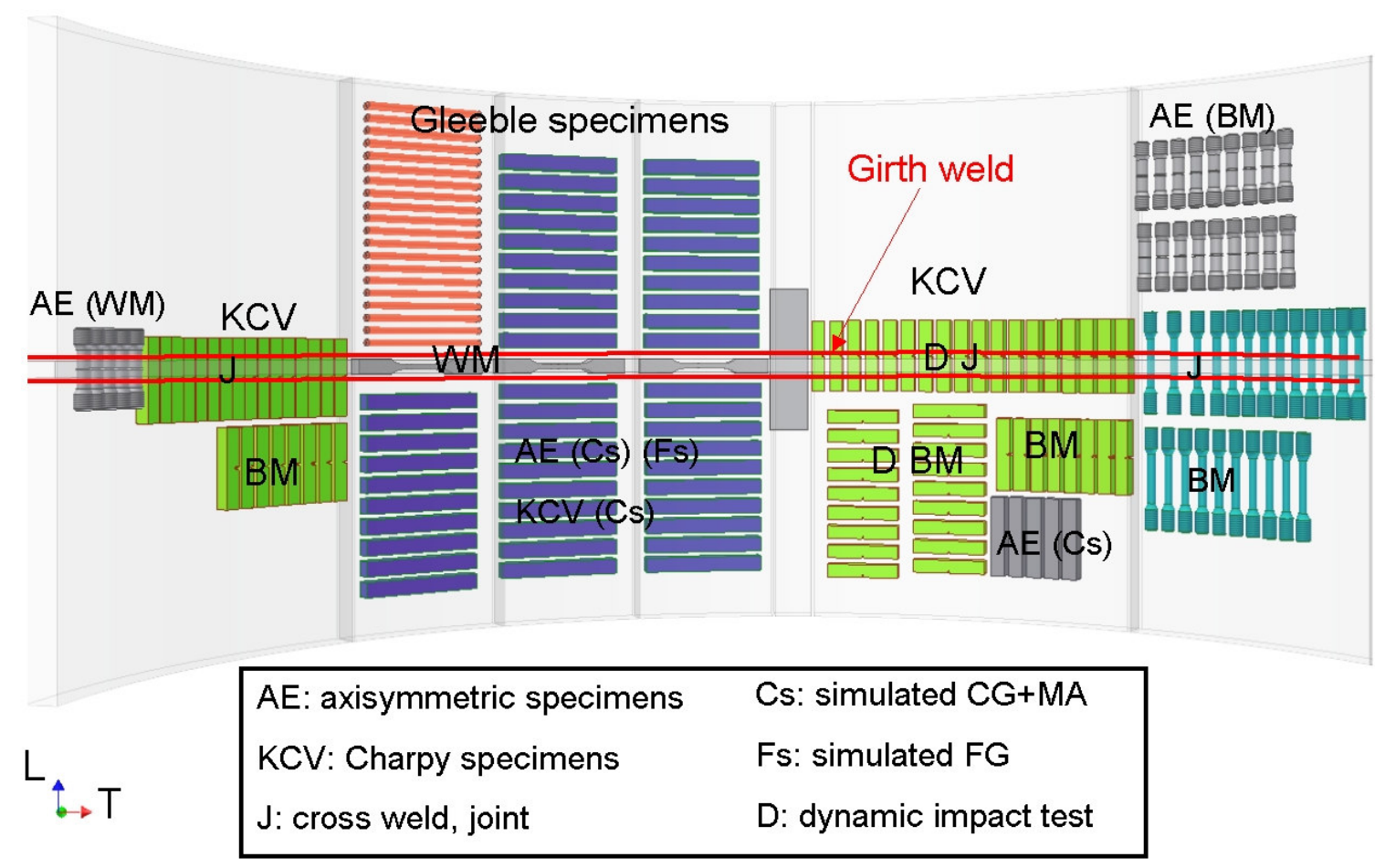

Figure 3. Sampling plane in the pipe and in the girth weld

Figure 4 shows the tensile curves of BM, WM and cross weld specimens. The weld is matched in yield stress (YSWM=YSBM), and overmatched in tensile strength (TSWM>TSBM), because the base metal of the pipe exhibits little work-hardening. The cross-weld curve is lower, indicating that the HAZ has both lower YS and TS.

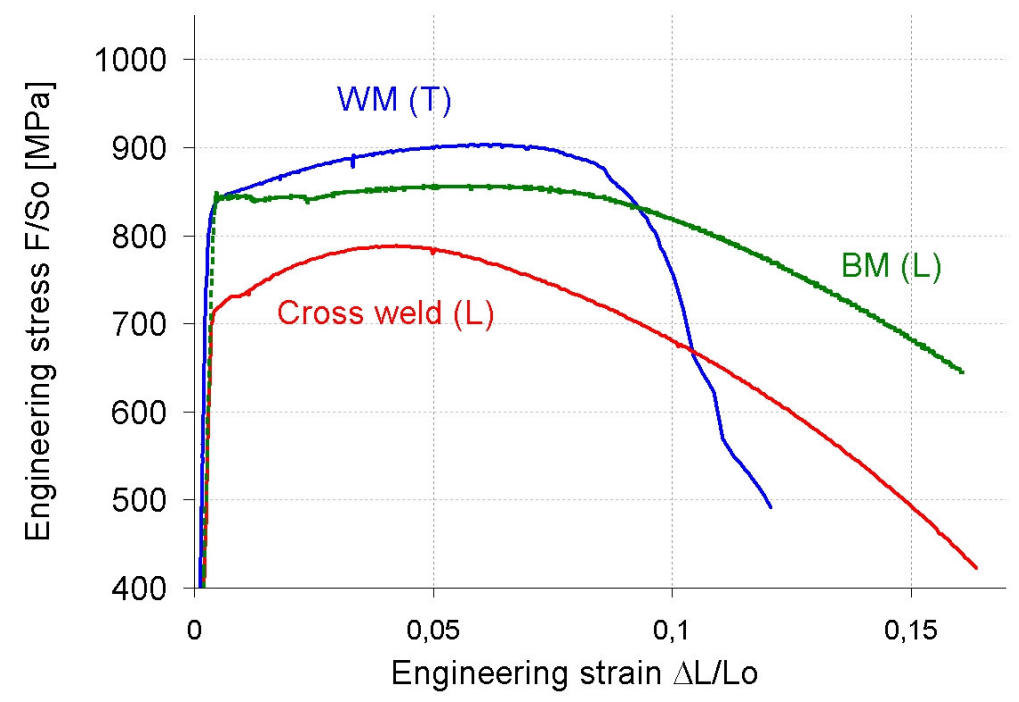

Figure 4. Engineering tensile stress-strain curves (WM, BM, cross weld) at room temperature 


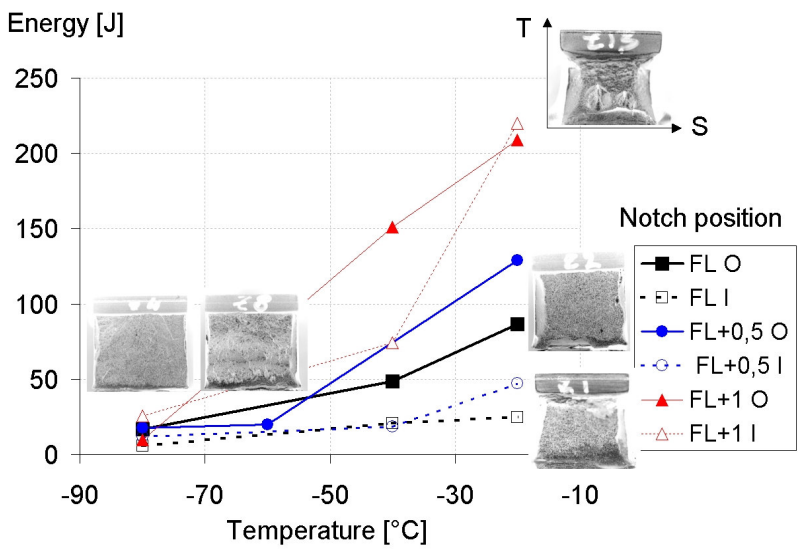

Figure 5. Results of Charpy impact tests. (FL+x : notch located $\mathrm{x} \mathrm{mm}$ from the fusion line in the base metal ; O or $\mathrm{I}=$ Outer or Inner subsurface of the tube wall)

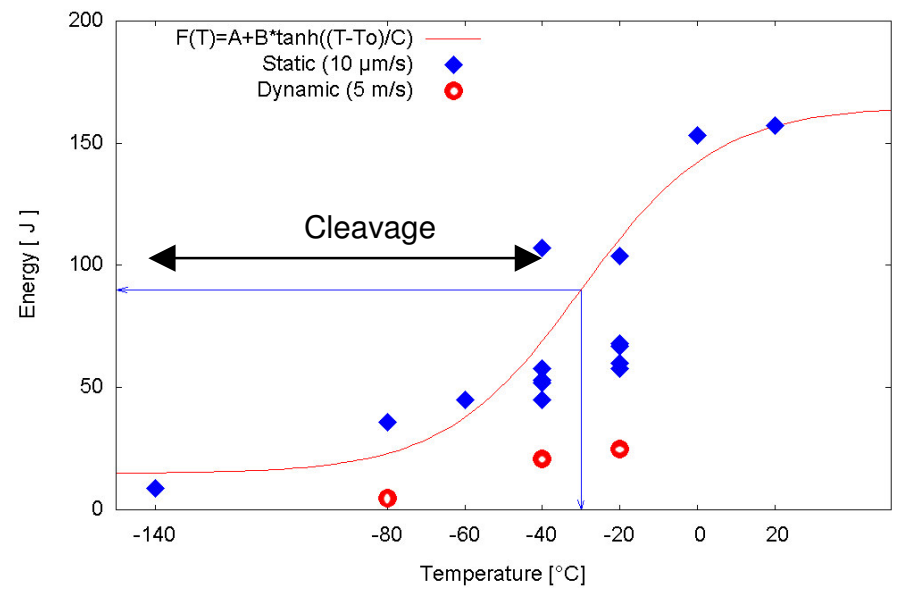

Figure 6. Results of quasi-static Charpy tests (blue diamonds) compared to the dynamic Charpy tests (red circles), notched at FLI

The bending specimens were notched at the fusion line (FL) and in the HAZ at 0.5 and $1 \mathrm{~mm}$ from FL. Figure 5 represents the fracture energy of Charpy specimens versus temperature. The further the notch from the fusion line, and/or the higher the temperature, the higher the fracture energy is. The impact tests show low fracture energy at $-20{ }^{\circ} \mathrm{C}$, when the specimens are cut from the inner subsurface of the tube wall and the notch is located at the fusion line (FL I). Brittle fracture of these specimens is systematically located along FL in the CG zone, which consists of upper bainite, and could contain some martensite-austenite constituents.

The results of fracture energy for quasi-static and dynamic bending tests with Charpy specimens notched at FL I are compared (Figure 6). The fracture energy is higher for the quasi-static tests. The brittle/ductile transition, determined at the middle of the transition curve, using quasi-static Charpy V-notch tests, appears at $-30{ }^{\circ} \mathrm{C}$.

\section{Thermal welding cycle simulation}

The girth weld joint contains a HAZ which is too small to be mechanically tested. It was necessary to reproduce it in larger dimensions. A thermo-mechanical simulator Gleeble was used to recreate two HAZ in base metal blanks:

the first one is the brittle zone identified in the previous section, i.e. the CGHAZ with MA constituents (Cs),

- the second one has a low hardness, around $245 \mathrm{HV}_{10}$, formed with very small grains (Fs). It is not critical regarding fracture properties, but its low hardness could influence the local stress and strain fields in the neighbouring brittle CGHAZ.

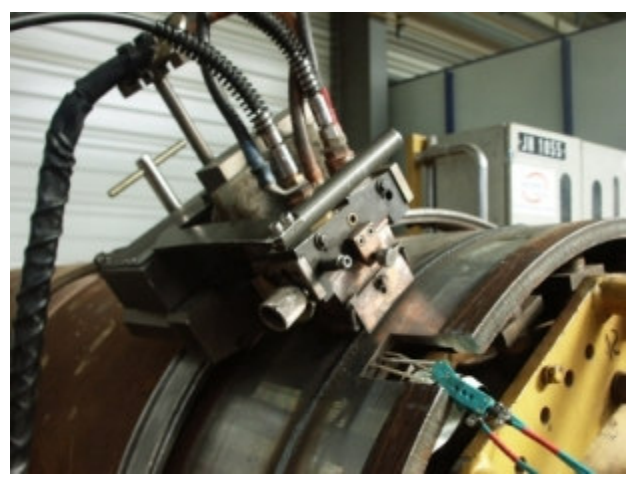

Figure 7. Temperature measurements in an actual welding operation

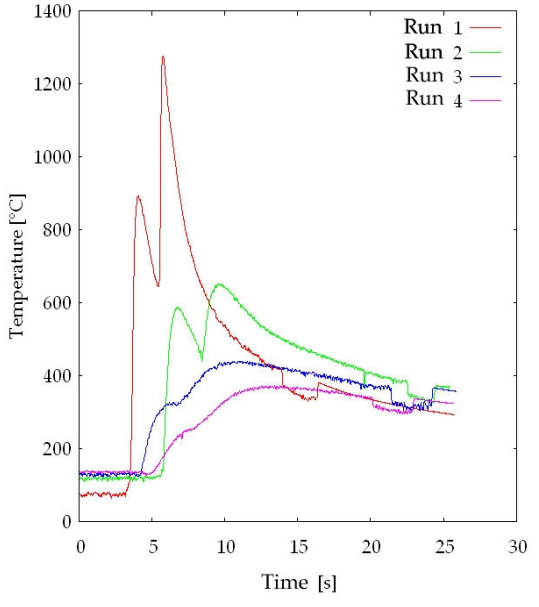

Figure 8. Typical thermocouple monitoring 
To work out the thermal cycle of HAZ, temperature measurements under the same operating conditions as for the studied joint were used. The monitoring was made by 4 thermocouples inserted in the heat affected zone of the joint (Figure 7). This welding operation is an automatic gas metal arc welding with two torchs. A monitoring example is shown in Figure 8, where the maximum of each curve is due to the run of one torch.

These measurements allow deducing:

i) the RYKALYNE model which was found to correctly fit the measured one-pass thermal cycle (Equation 1 and Figure 9) [4][5]

ii) the relationship between temperature and distance from the fusion line ( $\mathrm{x})$, to fit the thermal cycle experienced by the HAZ areas to be reproduced (Equation 2 and Figure 10) [5]

$$
F(t)=T_{0}+\theta_{1} \frac{\Delta t_{T_{1}}^{T_{2}}}{t} \exp \left(-\frac{\Delta t_{T_{1}}^{T_{2}} \theta_{1}}{\exp (1)\left(T_{p}-T_{o}\right) t}\right)
$$

where

$T_{p}=1500^{\circ} \mathrm{C}$

$T_{0}=100{ }^{\circ} \mathrm{C}$, preheat temperature

$t$ is time

$\theta_{1}=\frac{1}{\mathrm{~T}_{2}-\mathrm{T}_{0}}-\frac{1}{\mathrm{~T}_{1}-\mathrm{T}_{0}}$, with $T_{1}=500{ }^{\circ} \mathrm{C}$ et $T_{2}=800^{\circ} \mathrm{C}$

$\Delta t_{T_{1}}^{T_{2}}$ is the cooling time between $T_{2}$ et $T_{1}$

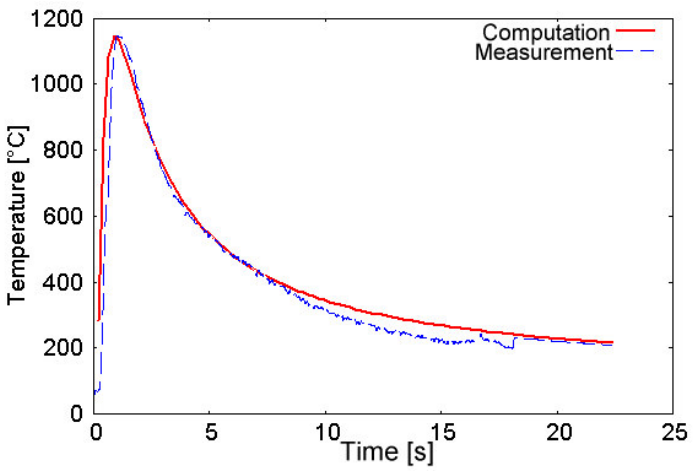

Figure 9. Temperature measurements at $1.5 \mathrm{~mm}$ from FL fitted with the Rykalyne equation (1)

$$
T_{p}(x)=T_{0}+\frac{1}{\frac{\pi e \rho C}{2 q / v} \times\left(x^{2}+2 R x\right)+\frac{1}{T_{F}-T_{o}}}
$$

where

$$
\begin{aligned}
& R=3.5 \mathrm{~mm} \\
& x, \text { distance between thermocouple and fusion line } \\
& T_{F}=1500{ }^{\circ} \mathrm{C} \text { and } T_{0} \sim 190{ }^{\circ} \mathrm{C} \\
& \rho=790010^{-9} \mathrm{~kg} \cdot \mathrm{mm}^{-3} \\
& C=490 \mathrm{~J} \cdot \mathrm{kg}^{-1} \cdot \mathrm{K}^{-1} \\
& q / v=\text { welding energy, } \mathrm{kJ} \cdot \mathrm{m}^{-1}
\end{aligned}
$$

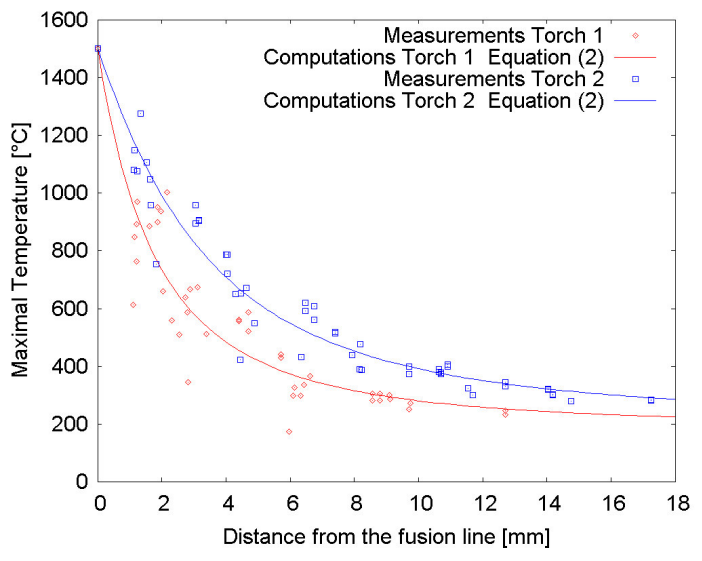

Figure 10. Maximal temperature versus distance from fusion line

These relations allow to define the best cycles to reproduce both selected microstructures (Cs and Fs).

Thermal cycle simulations were performed on samples measuring $11 \times 11 \times 60 \mathrm{~mm}$ using a Gleeble 1500, by applying a high electrical current through the metal sample, resulting in uniform resistance heating through the cross section over a length of approximately $5 \mathrm{~mm}$. Water-cooled copper jaws were used to grip the sample and provide high cooling rates. The temperature of the heated section was controlled using a K-type thermocouple connected to a computer system programmed to reach predetermined temperatures, which are relevant to HAZ thermal cycles.

The samples were heated at a rate of $400{ }^{\circ} \mathrm{C} / \mathrm{s}$ to $500^{\circ} \mathrm{C} / \mathrm{s}$ up to the peak temperature and were immediately cooled. Two peak temperatures of $1250^{\circ} \mathrm{C}$ and $775^{\circ} \mathrm{C}$ were used for the Cs microstructure. One peak temperature of $900^{\circ} \mathrm{C}$ was used for the Fs microstructure. The cooling time used from $800^{\circ} \mathrm{C}$ to $500^{\circ} \mathrm{C}\left(\Delta T^{8 / 5}\right)$ was around 6 seconds for both microstructures (Figure 11). The microstructures (constituents, former austenite grain size) and hardness of both zones are similar to those of the corresponding zones of the real joint (Figure 12). 


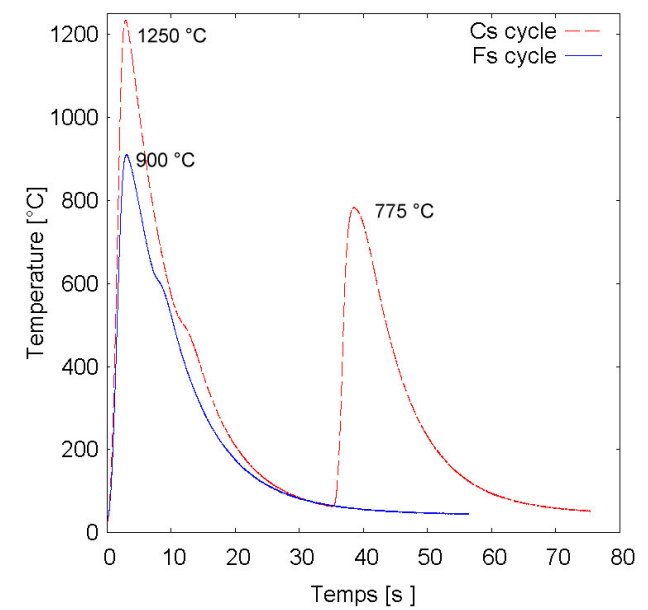

Figure 11. Typical cycles used to reproduce both HAZ

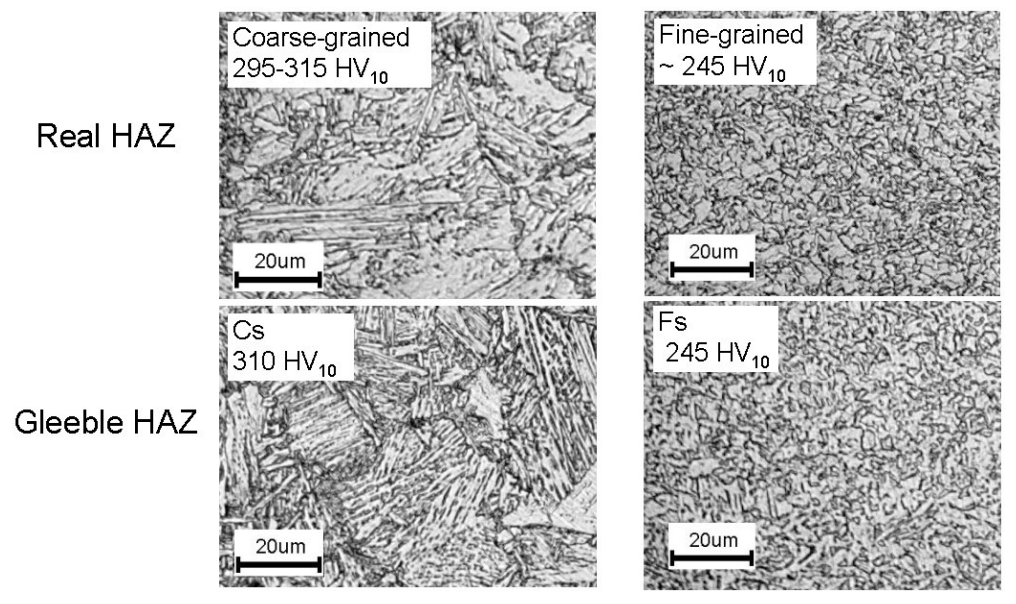

Figure 12. Real and simulated microstructures

\section{Future work}

The cycles allowed producing Cs and Fs blanks, which were then machined to axisymmetric notched specimens. The notch allows locating the stress and strain fields in the microstructure of interest. The mechanical tests are under progress (Figure 13), the curves will be used for the identification of model parameters.

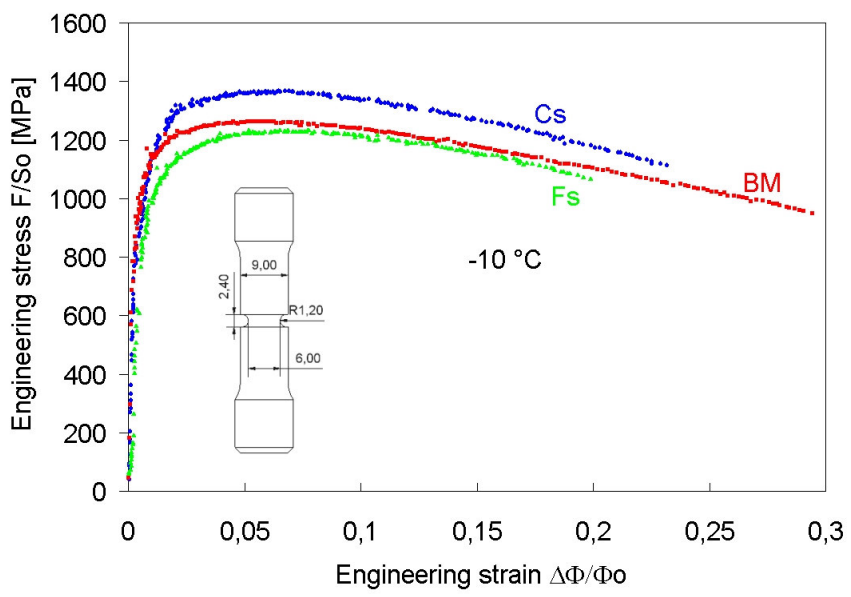

Figure 13: Tensile curves of notched samples for BM, Cs and Fs

The mechanical properties of the various zones of the girth weld will be introduced in a numerical finite element model code Zebulon Z8.4 [6], together with a statistical brittle fracture criterion to describe the behaviour of this "multi-material" assembly.

The geometry of the weld is complex due to the presence of four metallurgical areas (BM, WM, CGHAZ and FGHAZ) that need to be distinguished. In addition, due to the weld geometry, the fusion line is inclined with respect to the T-direction. Fine finite element meshes are also required to precisely evaluate strains and stresses in the failure zone. Meshes are generated using the Opencascade modeller [7] together with the 3D mesh generator developed at INRIA [8] which produces regular tetrahedra (Figure 15). An example of a preliminary calculation is shown in Figure 15 in the case of a cross weld Charpy specimen. 


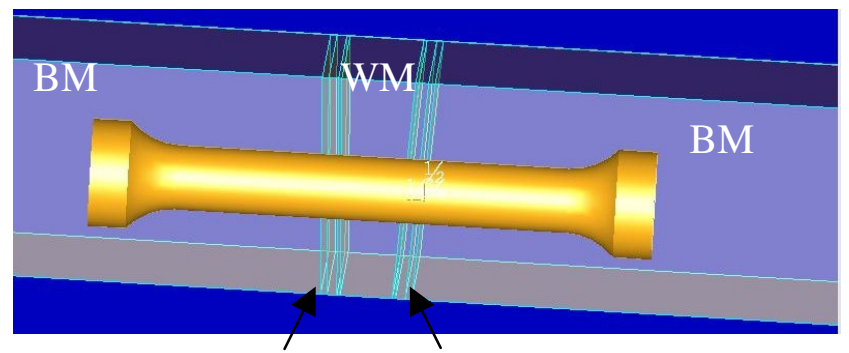

FL

FL

Figure 14. Specimens visualizations in the weld with OpenCascade, before meshing
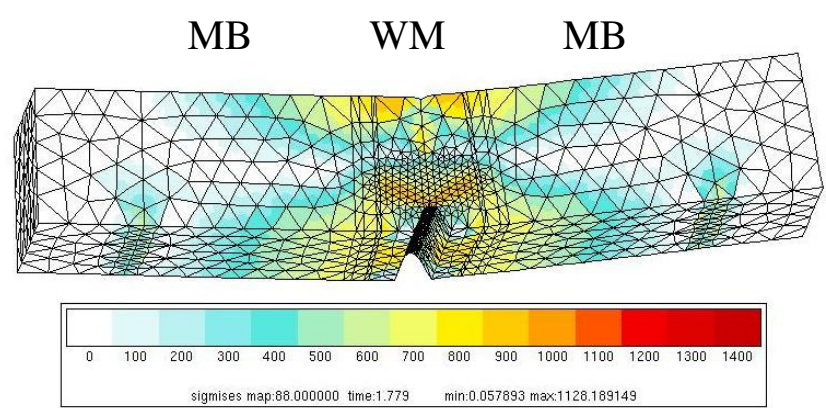

Figure 15. Computation cross weld with BM and WM behaviours

\section{Conclusions}

The low toughness of the Charpy tests notched at $\mathrm{FL}$ at $-20^{\circ} \mathrm{C}$ underlines the importance to take into account the $\mathrm{HAZ}$ for the computation. Two HAZ were selected, simulated and mechanically tested. The BM, WM, Cs, Fs behaviours will be introduced in a finite element model code to predict the rupture of the real girth joint.

\section{Acknowledgments}

The material was provided by EUROPIPE, welded by SERIMER DASA, while the impact tests were performed by GDF. Constant interest from SERIMER DASA, EUROPIPE, INSTITUT FRANCAIS DU PETROLE, TOTAL and GAZ DE FRANCE as well as financial support from CEPM (grant M9310/03) are gratefully acknowledged.

\section{References}

1. A. GLOVER, In Proceedings of the international Pipe Dreamer's Conference, edited by M.TOYODA and R. DENYS, Yokohama, Japan, 33-52 (2002).

2. Local approach to fracture, edited by J. BESSON, Presses de l'Ecole des Mines, Paris, France (2004).

3. A. LAMBERT-PERLADE, A.F. GOURGUES, J. BESSON, T. STUREL, and A. PINEAU, Mechanisms and Modelling of Cleavage Fracture in Simulated Heat-Affected Zone Microstructures of a High-Strength Low Alloy Steel, Metallurgical and Materials Transactions A, 35A,1039-1053, (2004).

4. RYKALYNE, N. N., Calcul des processus thermiques de soudage, Soudage et Techniques connexes (1961).

5. L. LAM THANH, R. PIQUES, A.F. GOURGUES, R. BATISSE, P. WIDENT, Investigation of the brittle failure properties of an A42 pipeline steel butt weld : comparison of the base metal, simulated HAZ and weld metal, 293-300, III, from "ECF 14 : Fracture mechanics beyond 2000", Proceedings of the 14th Biannual conference on fracture", Krakow, 8-13 Sept., vol. I/III, (2002)

6. J. BESSON and R. FOERCH, Large scale object-oriented finite element code design, Comp. Mech. Appl. Mech. Engng, 142, 165-187, (1997).

7. www.opencascade.org

8. www-rocq1.inria.fr/gamma/cdrom/www/blsurf/INDEX.html 